\title{
Notes
}

\section{Using Acronyms in Technical Writing}

\author{
Michael P.Jordan \\ Queen's University at Kingston
}

Acronyms serve two main purposes: as shorthand versions of well-established topics, and as a concise way of re-entering a topic into the text. For the second purpose, they form part of the system of lexical connection, along with repetition, synonyms, generic nouns, names, substitution (pronouns) and various clausal systems. A third reason for using an acronym is that it may be better known than the full name; examples are the technical terms Avo and Radar, the medical terms ASA and AIDS and the financial terms RRSP and TSE. Thus even if a new acronym is not used again in the text, it may still serve this third purpose:

(1) Alberta gets advanced monitors

A new generation of Remote Terminal Units (RTUS) designed for community services and environmental monitoring has been unveiled in Edmonton (Design Engineering, August/September 1998, p.8)

Although remote terminal units are quite well known to these readers, they may be better known as RTUs. Therefore, the acronym is included here as well as the full meaning even though it is not used again in the text.

These notes provide a brief introduction to the use of acronyms in place of organisation names and technical topics. The several ways of introducing acronyms into the text are discussed and exemplified. Final points discussed are the use of plural and possessive acronyms and the choice of the form of indefinite article preceding the acronym. The approach taken is that of describing actual language use through the study and use of published examples of text. 


\section{Names of Organisations}

Some acronyms of organisations (e.g., NATO, RCMP, USA) are so well known to readers it would be insulting to include an explanation, whereas others are not known by readers and their meanings must therefore be included in the text. The acronyms for some companies (e.g., IBM, CIBC, BMW, AT\&T) have become so well established few writers refer to their full names anymore. Indeed, neither do the companies themselves:

(2) This feature article is sponsored by IBM IntelliStation. A powerful graphics workstation and PC all in one. IBM IntelliStation. Nothing gets in the way of a good idea. IBM® Solutions for a small planet. (full page advertisement Mechanical Engineering, June 1997, p.75)

In recognition of the importance of their acronym, International Business Machines have actually registered it as a trademark. Not all companies have achieved such a level of recognition, and the assumption that they have can result in poor communication:

(3) SAP Canada names new executive, restructures

SAP Canada Inc. has appointed a new general manager and will tighten its relationship with its us counterpart. Carol Burch has replaced Robert Beauchemin, previously president of SAP Canada. (Computing Canada, January 22, p.16)

The assumption in Example 3 is that all readers will know what SAP means in this context. If there is any doubt at all, it is better to give the full name.

Many companies rely on partial acronyms (e.g. NORTEL, FEDEX), using parts of the words they represent (Northern Telecommunications, Federal Express). Again, unless this is well understood by all readers, it is better to provide the full name:

(4) PlenCo's phenolic resin and material manufacturing operations drive cost efficiency and reliability

PLENCO's extensive facilities are among the best engineered, equipped and maintained in the plastics industry...

PLENCO Plastics Engineering Company (end of advertisement, Automotive Engineering, January 1999, p.51) 


\section{Technical Topics}

As with some organisations, use of acronyms instead of the full names for technical topics is appropriate and necessary when readers already know the full names (e.g., AC/DC, HP, R\&D, $/ \mathrm{O}, \mathrm{RMS}$ ). In fact to do otherwise might insult your readers, as you are indicating to them that you think they do not know basic standard acronyms. Alternatively, of course, they might think that you do not know them! Use of full names instead of acronyms would have been absurd in:

(5) A new 19-slot XPCI single-bridge expanded passive backplane combines the advantages of ISA bus technology with the high speed of local bus PCI. (Industrial Computing, September 1998, p.8)

Readers already know what these acronyms mean and failure to use them, or also including their full meanings as well as the acronyms, would have been inappropriate in this magazine.

Acronyms should not be used without explanation unless readers know what they mean. Failure to provide the meaning can cause at least annoyance and possibly miscommunication:

(6) Numerous brief [power] outages will occur during the year, however. These are a result of utilities switching, storms or other transient events. Most of these are short enough that they cause a UPS to transfer or the lights to blink, but will not normally cause a computer to restart. (Queen's Gazette, January 11, 1999, p.3)

The acronym had not been named before this point. We might guess that it means something like "University Power Switch", but that is not good enough. Although we are later told that the UPS switches to battery backup and buys time while the power system is restored, readers need to know exactly what UPS stands for.

\section{Introducing New Acronyms}

Where acronyms are being used as a shorthand method of re-entering the topic later in the text, both the full name and the acronym need to be included. There are several ways of doing this. The most-common method, used when it is assumed that none of the readers know the acronym, is to state the full name first followed by the acronym in brackets: 
(7) All Big Three automakers use a scanning laser vibrometer (SLv) from Polytec PI Inc. in Auburn, Mass., to analyze the vibrations of auto parts and components. The sLv analyzes an object to determine the sources of vibration. An SIV scan of a running engine or other structure gathers multifrequency phase and amplitude values at every point....(Mechanical Engineering, June 1997, p.26)

When, however, some readers might know the acronym and some might not (or if you do not know what readers know!), the acronym is placed first and the full meaning follows in brackets. Sometimes the acronym and its full meaning are not formally connected at all:

(8) AGM, golf mark gala day for CFPA

While the perfect July weather made little difference to the Canadian Fluid Power Association's annual general meeting at Devil's Pulpit near Caledon, Ont., it was a decided boon for the golf tournament which immediately followed. A series of committee reports constituted the bulk of the business.

Mike McKay updated the group on the CFPA's program of visiting middle school. (Design Engineering, August/September 1998, p.11)

The full form of the well-known AGM is given after the acronym just in case some readers needed it. However, it is so well known that a formal connection between the two would have been inappropriate. The meaning of CFPA may be less well known, and it does need to be given in the text, but again not formally connected to the acronym. For both acronyms, their use in the title also makes a formal connection less likely in the main text.

Introducing an acronym without a formal introduction in brackets immediately following the full name is ideal when its first use is very close in the text to the full name:

(9) The smaller system consists of the IImorrow Global Positioning System and a receiver set at 1.090 megahertz to capture the GPS squitter signals transmitted by other aircraft in flight to identify their positions. (Mechanical Engineering, June 1997, p.14)

Although GPS could have been introduced in brackets immediately after Global Positioning System, that is not necessary because the acronym is used shortly afterwards and it is thus clear what it represents.

The acronym is sometimes part of a larger topic and its meaning then has to be gleaned from the text: 
(10) CIO group says it's time to end the "Y2K hype"

Everybody is looking for a silver bullet for the Year 2000 problem - but there isn't going to be one. So says Catherine Aczel Boivie, chair of the Vancouver-based Chief Information Officers Association of British Columbia (CIOABC)...Aczel Boivie, who by day is cIo of the British Columbia Automobile Association, said Y2K hype has many origins... Nelson Tkatch, CIOABC vicepresident of membership, said clos can combat hype by educating their organisation's senior management. (Computing Canada, January 1999, p.4)

Although the full form of CIOABC is given, readers have to work out what CIO means. This presents no real difficulty, however.

\section{Final Points}

Adding a lower case $s$ usually creates the usual plural form for acronyms. The comma plus $s$ is occasionally used instead (e.g. CPU's), but that form is usually reserved for possessives (see Examples 4 and 8). Well-known acronyms are used in plural as well as singular form without previous introductions:

(11) The CPU card has Aaeon's High Drive feature that supports up to 20 peripheral cards on one backplane... The cPus use standard socket-7 mounting... These address a recently emerged set of considerations, particularly for industrial PCs....(Design Engineering, August/September 1998, p.26)

Usually the full singular form is used to create the singular acronym, which may be pluralized later if necessary, but sometimes the full plural form is used to create the plural acronym directly:

(12) A new one-device solution integrates incompatible programmable logic controllers, distributed control systems, remote terminal units (RTUs), and supervisory control and data acquisition systems easily, neatly and cleanly for the user....Multiprotocol support or port sharing enables a single serial port to communicate with many different types of RTUs. (Industrial Computing, September 1998, p.25)

Compare the reason for using RTUs here with that in Example 1; different readers are involved of course.

When the indefinite article is used with an acronym, an is used if the start of the acronym sounds like a vowel; otherwise $a$ is used. Some acronyms are read as words (e.g., NATO, CAD/CAM) although most are read as individual letters (e.g., CEO, 
BMw). Acronyms with first pronounced letters of A, E, F, H, I, L, M, N, O, R, S and $X$ are therefore preceded by an and not $a$ (e.g., an sLv [see Example 7], an AC motor).

However, some words starting with some of these letters may require the use of $a$ when the acronym is read as a word (e.g., a NATO officer, a MEMS approach). As the letter $U$ has a vowel and a non-vowel sound, that use determines the type of indefinite article used (e.g., an UNSCOM initiative, but a UNICEF program). The Word '97 Spelling and Grammar tool is not totally reliable for the use of indefinite articles with acronyms; it prefers an UNICEF to a UNICEF. The form of article choice can indicate the writer's knowledge of the subject: whereas most writers would use an SCSI, those familiar with electronics and computers would use a sCSI because sCSI is pronounced "scuzzy".

The two forms of definite article are spelled the same, but pronounced differently: the unmarked the (as in the book) is used when the following sound is a consonant, and the marked the (as in the egg) is used when the following sound is a vowel.

\section{Conclusions}

In technical and business prose, acronyms are often an indispensable way of communication. For those who already know the acronym, their use represents not just a handy short-form of communication, but also an expression of shared knowledge and communication practice. For those who do not know the acronyms used (or when the acronyms are newly coined), they present a useful method of re-entering large topics into the text in successive sentences - as subjects, objects or possessive adjectives. Progression of an acronym towards the status of an independent word, remote from its origin, shows very broad knowledge and acceptance of the meaning of the acronym within a given speciality.

There are several ways of introducing acronyms, and their use depends largely on the perceived level of knowledge and acceptance of the acronym by readers of the document. The less it is assumed that readers already know, or know of, the meaning of an acronym, the more necessary it becomes to connect it closely in the text to that meaning. The extreme opposite case is when readers fully understand the meaning of an acronym. In that case no connection with the full meaning is necessary; it could in fact be insulting as it implies that the writer thinks the readers do not know basic acronyms in the discipline.

The overall principle for use of the different forms of the indefinite and definite articles is based on how the following word (noun or adjective, acronym or not) sounds. Those that sound like a vowel are preceded by an and the rather 
than the unmarked $a$ and the, while those that sound like a consonant are preceded by the unmarked forms. This poses little difficulty when applied to acronyms, although difficulties can arise when writers are uncertain how a particular acronym is pronounced. 